\title{
2. Sorcery, Christianity and the Decline of Medical Services
}

\author{
John Cox and Georgina Phillips
}

\section{Introduction}

In Papua New Guinea (PNG), witchcraft and sorcery accusations appear to be proliferating and, in many cases, leading to horrific violence, torture and murder of those thought to be sorcerers (Chandler 2013). Our contribution to the debates about sorcery-related violence is to see it as the result of poverty and failing services. Following the medical anthropologist and infectious diseases physician Paul Farmer, we reject interpretations of sorcery accusations and violence as grounded in the ancient traditional culture of Melanesia. ${ }^{1}$ Instead, we see the resurgence of sorcery as an effect of poverty and social inequality, particularly the neglect of medical services and training (Farmer 1999).

Sorcery accusations are largely associated with untimely or unanticipated deaths, therefore the contest between these ways of thinking and biomedical understandings of disease and illness is important to examine. In this chapter, we argue that the explanatory power of biomedicine in PNG and Solomon Islands is hampered by several factors, not least the poor access to and resourcing of medical services. The reinvigoration of medical training and service provision is crucial to demonstrating the efficacy of biomedicine and improving health outcomes for PNG as well as combating the spread of competing understandings of illness and disease that give rise to maltreatment, social division, misogyny and violence.

This chapter draws heavily on the anthropological work of our friend Alice Street, whom we first met in Madang in 2009. Her insightful ethnographic studies of Modilon Hospital, the referral hospital for Madang Province (2009, 2010, 2011, 2014), have provided much of the grounding for the arguments we make in this chapter. However, we have our own experiences of Melanesian hospitals and the people who work in them, particularly doctors, whom Phillips has had particularly privileged access to as a senior colleague. Like Street, Cox is an anthropologist who has done fieldwork in Madang for his study of middle-class investors in 'fast money schemes' in PNG (Cox 2011, 2013; Cox and Macintyre 2014). Phillips is an emergency physician who since 2006 has worked

1 Here we use 'Melanesia' as a shorthand reference to PNG and Solomon Islands. 
closely with Papua New Guinean and Solomon Islander doctors completing their training in emergency medicine through the University of Papua New Guinea. This has included the establishment of a Visiting Clinical Lecturer Program at Divine Word University (Atua and Phillips 2014; Phillips et al. 2012). Phillips has also done medical capacity development work in Kiribati and Myanmar (Phillips et al. 2014) and has conducted programmatic reviews of emergency departments (EDs) in East Timor (2009) and Solomon Islands (2014). The reflections in this chapter draw on these experiences and on a recent (July-August 2014) visit to PNG by both authors. We also thank our dear friend Dr Vincent Atua, director of the ED at Modilon General Hospital, Madang, for years of stimulating conversations about these issues and for his comments on an earlier draft of this chapter.

\section{Emergency departments in Melanesia}

Here we focus on hospital EDs as sites where the social meanings of sorcery are enacted and contested. In their role of providing biomedical services, EDs are important places for the treatment of victims of violence arising from sorcery accusations. Sometimes relatives of people who have died will come to EDs seeking a post-mortem medical diagnosis in order to resolve accusations of sorcery (cf. van Amstel and van der Geest 2004). EDs are also places where staff, patients and relatives publicly reproduce sorcery discourse and therefore indirectly legitimate violence. EDs are relatively recent spaces in hospitals around the world. Traditionally, they have been the domain of unsupervised junior doctors and often used as a place of last resort for underperforming medical and nursing staff. In PNG, emergency medicine is in its infancy (Aitken et al. 2003). Only 10 local emergency physicians have graduated through the specialist training program at the University of Papua New Guinea Medical School that commenced in 2002. Of those 10, only six remain working in the public health system in PNG. Solomon Islands has no emergency medicine specialists.

Emergency medicine concerns itself with the prevention and clinical care (diagnosis and management) of all acute and urgent health problems across the entire spectrum of illness and injury. Emergency medicine cares for all types of patients at every stage of life, and also incorporates pre-hospital care - the delivery of first aid and supervised transport to hospital for people who need urgent medical and nursing attention. Emergency care specialists prioritise clinical care according to urgency rather than type or severity of health problem (Hsia et al. 2010; Razzak and Kellermann 2002). Emergency medicine is a population-based discipline that reflects the demographics and health problems 
of a community when preventative and primary care systems are insufficient. All of these factors make EDs invaluable places from which to observe emergent trends both in health and society more generally.

In Melanesia, training in emergency medicine has largely been confined to doctors, despite the integral team-based nature of emergency care practice. Since the infancy of the emergency medicine specialist training program at the University of Papua New Guinea, Australasian emergency physicians have been involved as clinicians, teachers and peer-supporters of doctors from PNG, Solomon Islands and Vanuatu (Curry et al. 2004). Some of those doctors have spent time in Australian EDs to practise emergency medicine and experience advanced triage and other tools in a mature system as part of their specialist training. For nurses, training in emergency care has been much more ad hoc; confined to team-based short-course teaching and the efforts of a few dedicated nurses. One small program has involved nurses from the EDs of St Vincent's Hospital in Melbourne and the Port Moresby General Hospital visiting each other's environments as an educational exchange (Phillips 2013).

There are several notable exceptions, such as the new ED at the Port Moresby General Hospital but, generally, EDs in Melanesia are poorly designed and illequipped to provide core components of emergency care. Space for resuscitation is often cramped and crowded and basic necessities such as oxygen, suction and essential medicines are frequently missing. Rooms for acute care delivery are poorly lit, poorly ventilated and with little amenities. Areas for triage, waiting patients and patients requiring observation were never incorporated into past ED building designs, and so those functions are now delivered outside or in an ill-fitting space. Basic investigations such as X-rays and simple blood tests are often impossible to obtain in a timely manner, thereby substantially limiting diagnostic ability in emergency situations, quite apart from the issues regarding tests discussed in Street (2011) and later in this chapter. In the vast majority of EDs around the region, there are no clinicians with the essential skills and knowledge for emergency care.

\section{Hospitals as spaces of contested meanings and practices}

Anthropologists have argued that hospitals are not simply places governed by biomedical ideals. Rather, a range of beliefs and practices shape day-to-day behaviour within hospitals, including the interactions between patients, their relatives, doctors, nurses and hospital management. Hospitals in Melanesia may even play significant roles in negotiating compensation claims (van Amstel and van der Geest 2004). We endorse Zaman's insight that 
the hospital is not an isolated subculture or an 'island', rather it is a microcosm of the larger society in which it is situated. A hospital ward is therefore a mirror that reflects and reveals the core values and norms of the broader society. (Zaman 2005:18, cited in Street and Coleman 2012:7)

Christianity is constitutive of the public realm in PNG, Solomon Islands and other Pacific islands countries (Tomlinson and McDougall 2013). This extends to health services, which were often initiated by Christian missions. Hospitals in Melanesia are often run by churches, but even notionally secular government facilities are Christian in practice. Hospitals host interdenominational religious fellowships for their staff and are regularly visited by evangelists and other religious practitioners, who may preach to patients and certainly leave religious magazines and so forth in the hospital (Street 2011). However, this religious permeation of the hospital space sometimes meets limits. In Port Moresby a recent controversy over Pentecostal groups advising AIDS sufferers to abandon their medication in favour of faith healing has led to a ban on visitors praying with patients (Cochrane 2014; Eves 2008).

Street $(2010,2011)$ has shown how Christian practices of belief function in the PNG hospital setting, where patients attempt to demonstrate their moral worthiness as a means of accessing curative services. As Eves (2010:497) has noted, Christianity has a long pedigree of associating illness with immorality that underpins this logic of personal moral regeneration. In Madang — and more widely in Melanesia - many nurses feel free to proselytise to patients, or offer them specifically Christian moral exhortation and prayer. This pastoral role is not seen as incidental to their nursing responsibilities but is integrated into their biomedical practice, which is seen as 'God's work' (Street 2010:262). Rather, a number of nurses see themselves as active agents who are more directly involved with patients than doctors and who therefore can claim a unique efficacy in the curative process. According to Street (2011:7), the ward nurses she observed believed that their expertise included counselling patients about their illness, allaying fears of sorcery and persuading them to turn to God. This may not characterise all nurses in Melanesia, but certainly forms part of the context of biomedical practice in Madang and elsewhere, as the following example also illustrates.

\section{Prayer and the demon-possessed girl}

Prayer has long been a complementary accompaniment to biomedicine in Melanesia (and well beyond). Nevertheless, it seems that there are new trends within the formal health system that go beyond a complementary relationship, threatening to displace the logic and practice of biomedicine, and shifting the 
balance towards spiritual diagnostics and treatment. In some cases, the sick who seek out medical treatment may even be blamed for their lack of faith in God, who is thought to be able to cure all illnesses. This is particularly noticeable in places influenced by Pentecostal teachings on bodily health as contingent on the believer's faith (Barker 2003; Eves 2010).

Explicit Christian medical practice is less common among doctors. However, Phillips recently witnessed the treatment of a young girl in the Solomon Islands National Referral Hospital in Honiara who was assumed by doctors and nurses alike to be 'demon possessed'.

The 11-year-old schoolgirl had been rushed to the resuscitation room of the ED by her family in an agitated state. The junior doctor, 'Kathy', who was attending her described the girl's initial presentation as 'struggling' and reported her yelling at one stage 'Satan! Satan! Satan!'. Apparently the girl had gone to school in her normal, well state that morning, and suddenly became physically agitated and emotionally distressed with 'yelling and struggling'. Family had been called to collect the girl and had secured transport to get her to hospital where upon arrival she was ushered into the resuscitation room by the ED nurses. Kathy was rapidly on hand and with the nurses' help administered a dose of sedative medication by intramuscular injection. Nothing happened immediately, so the family continued to hold the struggling and distressed girl down on the ED bed so that another dose of commonly used sedative was injected.

When asked what she thought was going on, Kathy's immediate working diagnosis was 'satanic possession'. 'Could it be anything else?' Phillips asked; a common technique she uses when teaching or supervising junior staff back in Australia to trigger more critical thinking about the clinical presentation. Kathy's response was: 'Not really. I know it's difficult for outsiders to understand, but this is part of our belief system here in Solomon Islands. It's quite a common occurrence. I mean, I should consider mental or organic illness, but I really think this is demon possession.' McDougall (2013) has noted that the modern public culture of Solomon Islands is highly evangelical and Kathy's rendering of 'our belief' fits with this interpretation.

For Kathy and the other ED staff, the proof of supernatural origins of the girl's symptoms was the lack of immediate response to the biomedical treatment of the sedative medication. 'We gave the diazepam and haloperidol, and nothing happened.' The fact that the girl didn't immediately calm down after receiving Western medicine was clear reinforcement of a supernatural diagnosis, rather than a pharmacological understanding of the likely time of onset of these drugs when administered via an intramuscular pathway (which was likely to be delayed by 15-20 minutes or even longer). 
Phillips asked Kathy what the treatment for 'satanic possession' was. 'Prayer' was the confident response. By this stage, the young schoolgirl was deeply asleep (as a result of the repeated doses of sedative that she had received) and her family gathered around her rubbing and massaging her limbs. A Melanesian Brother (Anglican lay brothers known in Solomon Islands and Vanuatu as tasiu: Taylor 2010, in press) had been summoned and had commenced reciting prayers at the head of the bed. He also sprayed water from his home-made spray bottle in a ritual bewildering to Phillips - he alternated between spraying water onto the girl's body and into his own mouth (cf. the 'water of life' described in Eves 2008 and 2010). All of this 'treatment' was carried out on one of the three trolleys available in the resuscitation room, while family members of critically ill patients and staff also in the room looked on, or gave support. Here the tasiu had replaced the doctor and nurses as the expert curative practitioner.

A few hours later, Phillips learnt that the girl had woken up calm and been discharged into the care of her family. The possibility of an alternative diagnosis such as mental illness, physical disease or her exposure to a harmful or traumatising event was never to be considered. This story is but one example of the overlapping domains of knowledge that operate within Melanesian hospitals where biomedical models often give way to other understandings of illness and curative processes that privilege supernatural agency. It can also been seen as evidence to support Denoon's (1989) observation that women are systematically underserviced in Melanesian hospitals.

\section{Sik bilong marasin, sik bilong ples and white doctors}

Cox recently asked 'Byron', a well-educated young Papua New Guinean academic, whether he believed in sorcery. Byron shifted in his seat and answered, 'Not really but sometimes when there are limits to scientific medicine; when the doctor doesn't know what is wrong with the sick person, then we look for other explanations'. Byron, who comes from a relatively affluent Pentecostal family and grew up entirely in Port Moresby, did believe in sorcery but as an explanation of last resort only to be deployed when biomedicine has tried everything and reached its limits. As another doctor from Madang told us:

When I tell patients that I am unable to diagnose the cause of their illness or if I say that I'm not sure what it is. It is often a reflection of my own lack of knowledge, compounded with a lack of diagnostic and specialist support. The patients see me as a know-it-all — so if I can't diagnose or fix the sickness then their logical conclusion would be, 'If the doctor can't figure it out, then it must be sorcery related'. Typically patients 
will say, 'Ok doctor, we know what the cause is' or 'em sik bilong ples'. "We just brought him to you to exclude a "white man's sickness" and if you say he hasn't got that then it's probably a "sorcery-related illness" and we will take him to a glasman [Tok Pisin: diviner]'.

It is not uncommon for doctors to be approached as expert witnesses to conduct autopsies with the purpose of adjudicating whether sorcery was the cause of death, again with the assumption that an identified medical diagnosis would rule out sorcery but that any failure of biomedical explanation would imply the use of sorcery. This does not always work. One Papua New Guinean doctor told us that he had returned to the village for a relative's funeral and took the opportunity to explain that his uncle had died of cancer, not sorcery. This expert advice was ignored, when several days after he had gone back to town some of his relatives attacked suspected sorcerers (also relatives), assaulting them and burning down their houses. The doctor was dismayed that his informed opinion had been set aside in favour of listening to a glasman, particularly when all the protagonists were relatives. He himself is seen as part of an educated and successful family and now feels that his reputation is in tatters and is paying reparations for the damage done by his cousins. He is also shocked at how easily family ties and respect for people were replaced by the fervid violence of sorcery accusations.

Taylor (in press), writing of Vanuatu, has made the argument that strenuous denunciation of black magic tends to reinforce beliefs in sorcery. A similar point is made by Piot (2010) in his account of the advance of Pentecostalism in West Africa. There the spread of militant Christianity intolerant of tradition and equating it with sorcery actually reaffirms the efficacy of sorcery by attributing it to the powerful agency of Satan. Similar patterns have been observed in the public life of PNG, particularly around the 2013 controversy over the removal of allegedly satanic carvings in the national parliament (Eves et al. 2014).

Taylor (in press) notes that contemporary Melanesian sorcery and Christianity emerge from the same system of thought (cf. Barker 2003). Christian ritual and practices of sorcery both mobilise supernatural powers for good or evil and the Christian tasiu has a counterpart in the kleva (Bislama: sorcerer). Both may access sacred power for curative results as Street's (2011) example of the glasman (see below) also indicates. Dundon (2007) also documents groups of charismatic Christian women 'prayer warriors' who identify sorcerers and perform healing rituals, often in health centres.

A typical point of view that we heard most recently in a conversation with 'David', a junior medical officer in Madang, also describes sorcery as a healing power. David articulates these domains as a temporal sequence: 'Patients are using sorcery [meaning traditional medicines] in the village [to heal themselves] but then when that treatment doesn't work, they go to the clinic but there are 
no drugs there, so they come to the hospital, so by that time they are very sick and there is not much we can do for them. So the hospital gets a reputation as a place where people die.'

Street describes a similar understanding of illness and injury among the patients and staff at Madang Hospital. There, sickness was often described in terms of severity, rather than as the manifestation of a particular illness identified through diagnostic processes (Street 2011). Patients distinguished between illness that is curable by biomedical means (Tok Pisin: sik bilong marasin) and that which biomedicine cannot cure because of its supernatural or traditional origins (sik bilong ples: 'village sickness'). Burton et al. (2013) note that sik bilong ples and sanguma (sorcery) are often used interchangeably. In the hospital, patients would seek out experts in countering sorcery - glasman who would prescribe remedies and even visit the patient in the ward. However, rather than sik bilong marasin implying a biomedical understanding of illness and its treatment, Street argues that this term denotes a racialised cultural domain (cf. Bashkow 2006; Cox 2015) wherein 'white' medicine can cure 'white' sickness but only Papua New Guinean cures can heal Papua New Guinean illnesses (Street 2010). ${ }^{2}$ The racialised division of the origins of illness frequently has a moral valence (e.g. Dundon 2010). As we shall see below, this racial framework is also applied as a critique of hierarchical relationships between doctors and nurses (Street 2011).

\section{Forgetting sorcery?}

While patients may solicit the skills of the glasman to counter hostile sorcery, Street (2010) documents nurses who advise their patients to leave sorcery behind or put it out of their minds. This exemplifies proper Christian conduct in rejecting sorcery and is believed to assist in the curative process, not least by resolving troubling divisions with kin. Jealousy and other forms of broken relationships are believed to cause illness and even death and are certainly thought to provoke the use of sorcery by offended parties with the result that victims experience illness, injury or death (Strathern 1968). Street argues convincingly that the nurses' advice was not an epistemological rejection of sorcery beliefs but the marking out of a preferred moral course of action focused on turning to God for healing. Barker (2003:289) states that 'Healing becomes a matter of expressing a strong personal commitment to a distant deity rather than of making amends within the community'. However, Street's nurses appear to have integrated these two practices. While they advised patients to repair broken relationships, this was to be done with a clear focus on their own renewed relationship with God.

2 Eves (2010) describes a similar distinction between local and exogenous illnesses but notes that Lelet are pragmatic in searching for cures from various sources. 
While the nursing staff Street worked with in 2003, and in subsequent visits, may have urged their patients to reject all thoughts of sorcery, this discourse seems to be intensifying. In recent short visits to the EDs at Port Moresby General Hospital, Madang Hospital and Goroka Hospital, Phillips observed a proliferation of sorcery discourse among hospital staff. Sometimes, as in the temporal sequence outlined above by David above, 'sorcery' was simply a reference to traditional healing practices, which might have a magical dimension but lack the malicious powers that Eves (2013) argues should define sorcery proper.

However, in several other cases, such as the demon-possessed girl in Honiara, hospital staff betrayed a willingness to accept supernatural agency as the primary explanation of illness and injury, without reference to biomedical causes. Even allowing for the ideological permeability of hospitals as social spaces, the explicit sidelining of biomedical knowledge by nursing staff is rather surprising. In effect, the curative powers of 'white' biomedicine have been dismissed as not applying to an expanding domain of sik bilong ples. Indeed, proclamations of supernatural agency or sorcery seem to be deployed quite carelessly and have become quite normalised. This may reflect the advance of revivalist Christian ideas of illness where God has the power to heal any illness (regardless of the sik bilong marasin/sik bilong ples distinction) or may send illness as a punishment for sin or a test of faith (Eves 2008).

One example concerns a middle-aged woman brought in to the ED in Madang Hospital by a male relative. She'd been brutally assaulted with a hammer and large piece of wood, and came shuffling in to the department led by her companion, her swollen face partially covered with a cloth. Once laid down on the resuscitation bed, the woman's injuries could be inspected; multiple open wounds over her head and face were a result of the hammer attack, as well as deformed and swollen elbows on both arms, which had been deliberately smashed. The piece of wood had been used over her torso and back, which was already showing signs of severe swelling and bruising.

As the ED nurse, 'Meredith', attended to her wounds, Phillips asked what had happened. 'She's been attacked because she is a sorcerer' was the explanation, without any further detail. The explanation of the reasons or history behind the attack was not required or sought by the ED staff, and the patient's history simply became 'attacked because of sorcery'. This was repeated each time the patient was referred to within the department, or even altered to 'the sorcerer who has been attacked'. After an X-ray had been done to diagnose the broken bones, Meredith proceeded to cut off all the woman's hair in order to properly clean the scalp wounds. Phillips expressed sympathy for the patient, as Meredith reiterated that 'she was a sorcerer'. In carrying out her duties as an 
ED nurse, Meredith treated the patient dutifully but was seemingly oblivious to any further effects of apparently reconfirming the label of 'sorcerer', which had been the cause of horrific injuries to the woman.

\section{Spiritual disorder}

The second example of ED staff uncritically accepting the framing of illness or injury in terms of sorcery is of a small boy who had been referred to the Madang Hospital ED from a rural health clinic because of a gunshot injury. The attending clinician at the clinic (a nurse or health extension officer) had bandaged the boy's wounds in both his ankles and sent him and his mother on some transport in to town. Fortunately for the small boy, the gun and bullets used were almost certainly home-made, and his injuries not nearly as severe as initially feared, although a wound washout and removal of bullet shrapnel from the wounds was required in the operating theatre.

The referral letter stated 'shot in both ankles by sorcerers'. This was also the story repeated by the boy's mother, who provided some extra detail about how they were being chased by sorcerers and trying to hide in bushes, when the boy was shot in both ankles. Again, no further details were required or sought by the hospital ED staff, and the cause of injuries, as stated in the official referral letter, became the factual history of the patient's injuries: 'shot by sorcerers'. There was no need for any ED staff to question the legitimacy or delve into the story in any way; it was simply unquestionably accepted as fact, perhaps because of the practices of writing that Street (2011) has argued fail to close off diagnoses.

It is interesting to consider the absence of another possible framing of the violence against this boy and his mother in terms of raskols, PNG's notorious criminal gangs (Goddard 2005; Macintyre 2008). The threat of raskol violence is something of a national concern and certainly drives a burgeoning private security industry (Lusby 2014) and would seem to provide an adequate explanation of this boy's situation. However, the social disorder of raskolism has been transformed in this case into the spiritual disorder of sorcery. Roscoe documents moral panic over raskolism in East Sepik where raskols could use their 'ill-gotten gains' to 'alleviate the threat of retaliatory sorcery by buying off sorcerors' (Roscoe 1999:178). In this example, however, generalised moral panic over sorcery appears to have subsumed raskolism as the source of ubiquitous, malign violence (Kulick 1993). 


\section{Health systems in decline}

Across Melanesia, health systems are routinely decried as in decline (Wiltshire and Mako 2014). For PNG, the devolution of responsibilities to provincial governments appears to have been disastrous for health services. For rural populations, primary health care has effectively been withdrawn, except in areas considered to be mining enclaves (but see Burton et al. 2013). This national decline in access to medical services also implies a corresponding decline in access to authoritative biomedical explanations of sickness and death, allowing sik bilong ples and sorcery-based explanations to hold sway.

The decline of biomedical knowledge and authority has also left space for the proliferation of pseudoscientific cures. These include the Bio Disc, a glass disc sold online and said to have the ability to cure AIDS, cancer and other illnesses. Bio Disc has been promoted and sold by a number of hospital staff in both PNG and Solomon Islands. Indeed, a senior medical specialist from Solomon Islands once assured us that he had cured a child of a stomach complaint by shining a torch through the Bio Disc onto the child's abdomen. This specialist sells Bio Disc products when doing clinical rounds in provincial hospitals, using his medical expertise to give credibility to a scam. This information was volunteered to us at a formal dinner in a Chinese restaurant in Honiara, where it was clear that the junior doctors around the table regarded this spruiking of pseudoscience as an unethical abuse of the man's position. They did not believe that there was any reasonable prospect of effective redress through official disciplinary systems, a perception borne out in other perhaps more serious examples of senior doctors who are regularly absent from their posts or neglect their professional responsibilities in other ways.

Medical training is under stress in PNG and Solomon Islands. Both undergraduate and postgraduate clinical teaching rely heavily on the apprenticeship model, whereby inexperienced trainees learn at the patient bedside, mentored and actively taught by experienced clinicians. Immediately before and after completing the medical degree, medical students and junior doctors are usually required to complete a structured, supervised and assessed hospital-based learning program with clear objectives and requirements. Often these programs are significantly compromised through lack of supervision and assessment; the workload of the few engaged supervisors being overwhelming.

In severely under-resourced hospital environments, where there are barely enough doctors for even basic service provision, the role of the competent, experienced doctor as a teacher is impossible. In many hospitals, junior doctors and students are left to their own devices. They make critical clinical decisions without supervision and often progress through their career without access to 
ongoing medical education opportunities. Those senior doctors who are engaged in teaching and training rapidly become burnt out, as demands for their skills exceed the limitations of their personal goodwill and energy. Professional frustrations compound this, where doctors are forced to work below their level of skill and training as a result of limited resources and inadequately supported health systems. The few hospitals that can support teaching and training are still vulnerable to precarious staffing situations, whereby the loss of one or two senior doctors can rapidly render the department or hospital into a survival mode of service provision over perceived 'extras' such as staff education and medical teaching.

Divine Word University is the site of health extension officer training through a four-year Rural Health bachelor degree. Phillips has worked with Divine Word University over several years to improve the standard of training for health extension officers, which has previously been perceived as insufficient. Modern methods of medical education have yet to be adopted into the curriculum or teaching program, relying instead on limited didactic practices. Clinical training suffers the same stress as that for medical students and doctors outlined above, compounded by the double duties of senior doctors in the Madang Hospital to supervise both University of Papua New Guinea and Divine Word University trainees. The end result is health extension officers with limited knowledge and inadequate clinical skills to meet the requirements of independent healthcare practice, let alone meet public expectations of a high standard of quality and safety.

\section{The contestation of medical roles}

Even as the resources for primary health care centres falter and medical training struggles, Street's ethnography demonstrates that the hierarchical ordering of biomedical expertise is under sustained resistance from nursing staff and even doctors themselves. Street (2011) documents the ways in which doctors come under criticism from nurses for ordering too many laboratory tests. Many doctors appear to have internalised these ways of working and prefer to focus on managing the expectations of nurses lest they be seen to be operating as 'white doctors'. This term of disparagement is used to decry doctors who seek to assert a hierarchy in the hospital workplace over the more egalitarian structure that is based on the pastoral roles adopted by nurses. 'White doctors' are thought to neglect their relationships with others and only act on behalf of themselves. Often conducting routine activities such as the issuing of instructions on patient care or diagnosis is sufficient to upset this order of relationships and provoke a reaction from the nurses. 
If medical education, training and ongoing professional development continues to be under-resourced, then it is highly likely that doctors, health extension officers and nurses will lack the expert knowledge that is necessary to reassert the primacy of biomedical understandings of diagnosis. Curative practices that centre on this expertise and require a functioning hierarchy of roles in order to be effective are currently being undermined by Christian pastoral roles that privilege supernatural agency and so give credibility to sorcery as a cause of illness and injury. Sorcery accusations, then, are not only the effects of Christian ideology. They are the social outcomes of an impoverished system of biomedical service provision where the training of expert staff who are key to the production of effective health services is neglected.

\section{Conclusion: The failure of biomedicine and the rise of sorcery}

Burton et al. (2013), writing of an impoverished district in Morobe Province of PNG, have argued that sorcery is an effect of poverty that explains misfortune and illness but does so in an unsatisfactory manner that lowers expectations of health services and makes it unlikely that villagers will demand better services from government or their elected representatives. Although our experiences have been largely in urban centres and specifically hospitals, we agree with this analysis. Farmer (2010) makes a similar point, calling for more attention to be given to the structural causes of the poverty that causes illness.

In our view, the current resurgence of sorcery-related violence is best explained by reference to social inequality and poverty. However, the effects of poverty and inequality are manifold and include the shaping and reshaping of ideas of illness and injury. Like Farmer, we reject the interpretation of sorcery simply as a matter of cultural difference, of the persistence of Melanesian cosmologies of the body and society. Rather, we see the decline of medical services and training (not to mention the educational franchise) as a characteristic of modern Melanesian polities that are now marked by extreme inequality.

This is dismaying to us and to millions of Melanesians, many of whom turn to supernatural explanations of their situation, not least in various forms of revivalist Christianity. ${ }^{3}$ As access to quality health services retracts across Melanesia, communities lose their collective memory of the efficacy of biomedicine, reducing it to simply another option alongside magical means, or even an inferior option when compared with the healing power of God.

\footnotetext{
3 Vaughan (2010), however, notes a more structural critique of poverty among PNG highlands' young people involved in a critical reflection process using Photovoice.
} 
In re-establishing the efficacy of biomedicine in this context, EDs are crucial sites because of their role as the 'front door' of the biomedical system. It is imperative that ED staff receive excellent foundational medical and nursing education and that this be supported by ongoing professional development activities and skills training. In the experience of Phillips and many other foreign doctors who have worked in the region, there is a great hunger for this kind of training and support among doctors and nurses alike. We recognise that all of this is impossible in isolation and also requires a renewed political and bureaucratic commitment by the PNG and Solomon Islands governments and their partners to providing well-resourced healthcare systems.

\section{References}

Aitken, P., C. Annerud, M. Galvin, D. Symmons and C. Curry 2003. Emergency Medicine in Papua New Guinea: Beginning of a Specialty in a True Area of Need. Emergency Medicine 15:183-87.

Atua, V. and G. Phillips 2014. Integrating Global Health Training and Postgraduate Medical Education in Australia. Oral presentation, Australian Medical Association National Conference, Canberra, 23-25 May 2014.

Barker, J. 2003. Christian Bodies: Dialectics of Sickness and Salvation among the Maisin of Papua New Guinea. Journal of Religious History 27(3):272-92.

Bashkow, I. 2006. The Meaning of Whitemen: Race and Modernity in the Orokaiva Cultural World. Chicago: University of Chicago Press.

Burton, J. with T. Phillips and R. Lennie 2013. Failing to Articulate the Causes of Poverty: Witchcraft and Human Behaviour in the Bulolo District, Papua New Guinea. Paper presented at the Sorcery and Witchcraft-Related Killings in Melanesia: Culture, Law and Human Rights Perspectives Conference, The Australian National University, Canberra, 5-7 June 2013.

Chandler, J. 2013. It's 2013, and They're Burning 'Witches'. The Global Mail 15 February. www.theglobalmail.org/feature/its-2013-and-theyre-burningwitches/558/, viewed 22/8/2014.

Cochrane, L. 2014. From Journalist to Faith Healer in PNG. ABC Correspondents Report 27 July. www.abc.net.au/correspondents/content/2014/s4054427. htm, viewed 22 August 2014.

Cox, J. 2011. Prosperity, Nation and Consumption: Fast Money Schemes in Papua New Guinea. In M. Patterson and M. Macintyre (eds.) Managing Modernity in the Western Pacific. St Lucia: University of Queensland Press, 172-200. 
Cox, J. 2013. The Magic of Money and the Magic of the State: Fast Money Schemes in Papua New Guinea. Oceania 83(3):175-91.

Cox, J. 2015. Israeli Technicians and the Postcolonial Racial Triangle in Papua New Guinea. Oceania. In Press.

Cox, J. and M. Macintyre 2014. Christian Marriage, Money Scams and Melanesian Social Imaginaries. Oceania 84(2):138-57.

Curry, C., C. Annerud, S. Jensen, D. Symmons, M. Lee and M. Sapuri 2004. The First Year of a Formal Emergency Medicine Training Program in Papua New Guinea. Emergency Medicine 16:343-47.

Denoon, D. 1989. Medical Care and Gender in Papua New Guinea. In M. Jolly and M. Macintyre (eds.) Family and Gender in the Pacific: Domestic Contradictions and the Colonial Impact. Cambridge: Cambridge University Press, 95-107.

Dundon, A. 2007. Warrior Women, the Holy Spirit and HIV/AIDS in Rural Papua New Guinea. Oceania 77(1):29-42.

Dundon, A. 2010. AIDS and 'Building a Wall' Around Christian Country in Rural Papua New Guinea. The Australian Journal of Anthropology 21(2): 171-87.

Eves, R. 2008. Moral Reform and Miraculous Cures: Christian Healing and AIDS in New Ireland, Papua New Guinea. In L. Butt and R. Eves (eds.) Making Sense of AIDS: Culture, Sexuality, and Power in Melanesia. Honolulu: University of Hawai'i Press, 206-23.

Eves, R. 2010. 'In God's Hands': Pentecostal Christianity, Morality and Illness in a Melanesian Society. Journal of the Royal Anthropological Institute (N.S.) 16(3):496-514.

Eves, R. 2013. Sorcery and Witchcraft in Papua New Guinea: Problems in Definition. SSGM In Brief 2013/12. Canberra: State, Society and Governance in Melanesia Program, The Australian National University.

Eves, R. and N. Haley, R.J. May, J. Cox, P. Gibbs, and F. Merlan and A. Rumsey 2014. Purging Parliament: A New Christian Politics in Papua New Guinea? SSGM Discussion Paper 2014/1. Canberra: State, Society and Governance in Melanesia Program, The Australian National University.

Farmer, P. 1999. Infections and Inequalities: The Modern Plagues. Los Angeles and London: University of California Press. 
Talking it Through

Farmer, P. 2010. The Consumption of the Poor: Tuberculosis in the TwentyFirst Century. In H. Saussy (ed.) Partner to the Poor: A Paul Farmer Reader. Berkeley: University of California Press, 222-47.

Goddard, M. 2005. The Unseen City: Anthropological Perspectives on Port Moresby, Papua New Guinea. Canberra: Pandanus Books.

Hsia, R., J. Razzak, A.C. Tsai and J.M. Hirshon 2010. Placing Emergency Care on the Global Agenda. Annals of Emergency Medicine 56:142-49.

Jolly, M. and M. Macintyre. 1989. Introduction. In M. Jolly and M. Macintyre (eds.) Family and Gender in the Pacific: Domestic Contradictions and the Colonial Impact. Cambridge: Cambridge University Press, 1-18.

Kulick, D. 1993. Heroes from Hell: Representations of 'Raskols' in a Papua New Guinea Village. Anthropology Today 9:9-14.

Lusby, S. 2014. Preventing Violence at Home, Allowing Violence in the Workplace: A Case Study of Security Guards in Papua New Guinea. SSGM In Brief 2014/49. Canberra: State, Society and Governance in Melanesia Program, The Australian National University.

Macintyre, M. 2008. Police and Thieves, Gunmen and Drunks: Problems with Men and Problems with Society in Papua New Guinea. The Australian Journal of Anthropology 19(2):179-93.

McDougall, D. 2013. Evangelical Public Culture: Making Stranger-Citizens in Solomon Islands. In M. Tomlinson and D. McDougall (eds.) Christian Politics in Oceania. New York and Oxford: Berghahn, 122-45.

Phillips, G. 2013. Nursing Capacity Building for Emergency Care in PNG. IEMSIG: Newsletter of the International Emergency Medicine Special Interest Group of ACEM 9(2):19.

Phillips, G.A., J. Hendrie, V. Atua and C. Manineng 2012. Capacity Building in Emergency Care: An Example from Madang, Papua New Guinea. Emergency Medicine Australasia 24:547-52.

Phillips, G.A., Z.W. Soe, J.H.B. Kong and C. Curry 2014. Capacity Building for Emergency Care: Training the First Emergency Specialists in Myanmar. Emergency Medicine Australasia 26(6):618-26.

Piot, C. 2010. Nostalgia for the Future: West Africa After the Cold War. Chicago: University of Chicago Press. 
Razzak, J.A. and A.L. Kellermann 2002. Emergency Medical Care in Developing Countries: Is It Worthwhile? Bulletin of the World Health Organization 80(11):900-5.

Roscoe, P. The Return of the Ambush: 'Raskolism' in Rural Yangoru, East Sepik Province. Oceania 69(3):171-83.

Strathern, A. 1968. Sickness and Frustration: Variations in Two New Guinea Highlands Societies. Mankind 6(11):545-51.

Street, A. 2009. Failed Recipients: Extracting Blood in a Papua New Guinean Hospital. Body and Society 15(2):193-215.

Street, A. 2010. Belief as Relational Action: Christianity and Cultural Change in Papua New Guinea. Journal of the Royal Anthropological Institute (N.S.) $16: 260-78$.

Street, A. 2011. Artefacts of Not-Knowing: The Medical Record, Diagnosis and the Production of Uncertainty in Papua New Guinean Biomedicine. Social Studies of Science 42:1-20.

Street, A. 2014. Biomedicine in an Unstable Place: Infrastructure and Personhood in a Papua New Guinean Hospital. Durham and London: Duke University Press.

Street, A. and S. Coleman 2012. Introduction: Real and Imagined Spaces. Space and Culture 15(1):4-17.

Taylor, J. 2010. The Troubled Histories of a Stranger God: Religious Crossing, Sacred Power and Anglican Colonialism in Vanuatu. Comparative Studies in Society and History 5(2):418-46.

Taylor, J.P. in press. Two Baskets Worn At Once: Christianity, Sorcery and Sacred Power in Vanuatu. In F. Magowan and C. Schwarz (eds.) Conflicts and Convergences: Critical Perspectives on Christianity in Australia and the Pacific. Leiden: Brill Publishers.

Tomlinson, M. and D. McDougall (eds) 2013. Christian Politics in Oceania. New York and Oxford: Berghahn.

Vaughan, C. 2010. 'When the Road Is Full of Potholes, I Wonder Why They Are Bringing Condoms?' Social Spaces for Understanding Young Papua New Guineans' Health-Related Knowledge and Health-Promoting Action. AIDS Care: Psychological and Socio-Medical Aspects of AIDS/HIV, 22(S2):1644-51. 
van Amstel, H. and S. van der Geest 2004. Doctors and Retribution: The Hospitalisation of Compensation Claims in the Highlands of Papua New Guinea. Social Science \& Medicine 59(10): 2087-94.

Wiltshire, C. and A. Mako 2014. Financing PNG'S Free Primary Healthcare Policy: User Fees, Funding and Performance. Canberra and Port Moresby: Development Policy Centre and The National Research Institute. 
This text is taken from Talking it Through: Responses to Sorcery and Witchcraft Beliefs and Practices in Melanesia, edited by Miranda Forsyth and Richard Eves, published 2015 by ANU Press, The Australian National University, Canberra, Australia. 